\title{
Artificial Allomelanin Nanoparticles
}

Xuhao Zhou ${ }^{\dagger, \perp,}$, Naneki C. McCallum ${ }^{\dagger, \perp,}$, Ziying Hu ${ }^{\dagger, \perp}$, Wei Cao ${ }^{\dagger, \perp}$, Karthikeyan

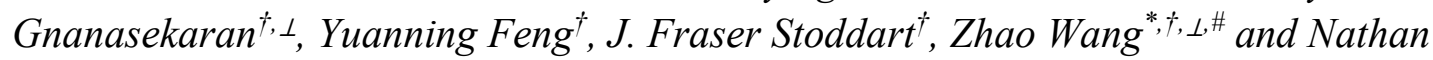

C. Gianneschi ${ }^{*}+,+, \mu, \perp, \#$

†Department of Chemistry, ${ }^{\star}$ Department of Materials Science and Engineering, and $\|$ Department of Biomedical Engineering, ${ }^{\perp}$ International Institute of Nanotechnology, Simpson-Querrey Institute, Chemistry of Life Processes Institute, Lurie Cancer Center. Northwestern University, Evanston, Illinois 60208, United States of America

\#Department of Chemistry \& Biochemistry, University of California, San Diego, La Jolla, CA 92093, United States of America

*E-mail: zwang12@uchicago.edu

*E-mail: nathan.gianneschi@northwestern.edu

${ }^{\S}$ X. Zhou and N. C. McCallum contributed equally to this work.

\section{Materials and Methods}

\section{Materials}

1,8-Dihydroxynaphthalene (1,8-DHN) $(95+\%)$ was purchased from Matrix Scientific. Dopamine hydrochloride (99\%) was purchased from Alfa Aesar. Tetraethyl orthosilicate (TEOS) (98\%) and sodium phosphate monobasic dihydrate (98\%) were purchased from Acros Organics. Laccase from Trametes versicolor ( $\geq 0.5 \mathrm{U} / \mathrm{mg}), 2$,2Diphenyl-1-(2,4,6-trinitrophenyl) hydrazyl (DPPH), ammonium hydroxide solution (28-30\%), sodium phosphate dibasic ( $\geq 99.0 \%)$, chitosan (molecular weight, 50,000$190,000 \mathrm{Da}), 1,1$ '-ferrocenedimethanol (Fc) (97\%) and hexaammineruthenium(II) chloride $\left(\mathrm{Ru}\left(\mathrm{NH}_{3}\right)_{6} \mathrm{Cl}_{3}\right)$ (99.9\%) were purchased from Sigma-Aldrich. Sodium hydroxide $(\mathrm{NaOH})$ (extra pure), potassium permanganate $\left(\mathrm{KMnO}_{4}\right)(99 \%)$, sodium periodate $\left(\mathrm{NaIO}_{4}\right)(99.8 \%)$, HPLC-grade acetonitrile $\left(\mathrm{CH}_{3} \mathrm{CN}\right)(\geq 99.99 \%)$, acetic acid (HOAc) ( $\geq 99.7 \%)$, sodium acetate trihydrate $\left(\mathrm{NaOAc}_{3} 3 \mathrm{H}_{2} \mathrm{O}\right)(99 \%)$, sodium dithionite (laboratory grade), and all other chemical reagents were purchased from ThermoFisher Scientific unless otherwise noted. Ethanol (200 proof) was purchased from Flinn Scientific. All chemicals were used as received. Ultrapure water was purified using a Branstead GenPure xCAD Plus system from ThermoFisher Scientific and used in all experiments. All grids for transmission electron microscopy (TEM) and scanning electron microscopy (SEM) were purchased from Electron Microscopy Sciences (EMS) unless otherwise noted. Cryogenic TEM (cryo-TEM) was performed on QUANTIFOIL $^{\circledR}$ Q250-CR2 holey carbon copper grids. Cell sections were imaged on 1-2 mm slotted copper formvar/carbon grids. Lacey carbon, 300 mesh, copper grids were purchased from Ted Pella. Grids were surface plasma treated using a PELCO easiGlow glow discharge cleaning system. Cell viability was performed using the thiazolyl blue tetrazolium bromide (MTT) reagent (98\%) from Sigma Aldrich. Neonatal human epidermal keratinocyte (NHEK) cells were donated by the Bethany Perez-White Lab at Northwestern University Feinberg School of Medicine. All other 
cell culture reagents were acquired from ThermoFisher Scientific.

\section{Instrumentation}

SEM images were acquired on a Hitachi S4800-II cFEG SEM and a Hitachi SU8030. Dry state TEM of nanoparticles was conducted on a Hitachi HT-7700 biological TEM at an acceleration voltage of $120 \mathrm{kV}$. Cryo-TEM experiments were performed on a JEOL ARM300F (300 kV) with a cryo holder and transfer station (Gatan Inc., USA) operating at $\sim-170{ }^{\circ} \mathrm{C}$. UV-Vis spectra were recorded using a NanoDrop 2000c UVVis spectrophotometer. Fourier transform infrared spectrometry (FTIR) spectra were obtained on a Nexus 870 spectrometer (Thermo Nicolet). Electrospray ionization mass spectrometry (ESI-MS) spectra were acquired on a Bruker AmaZon SL. Liquid chromatography-mass spectrometry (LCMS) experiments were conducted on a Bruker AmaZon X. Analytical high-performance liquid chromatography (HPLC) analysis was performed on a Jupiter $4 \mathrm{u}$ Proteo 90A Phenomenex column $(150$ x $4.60 \mathrm{~mm})$ using a Hitachi-Elite LaChrom L-2130 pump equipped with UV-Vis detector (Hitachi-Elite LaChrom L-2420). Matrix assisted laser desorption/ionization-time of flight mass spectrometry (MALDI-TOF MS) spectra were obtained on a Bruker AutoFlex-III. Solid-state NMR (ssNMR) spectra were recorded on a Mercury 400 (Bruker Avance III HD) equipped with Bruker 4mm HX probe. Hydrodynamic diameters and zeta potentials were measured on a Zetasizer. Continuous wave electron paramagnetic resonance (EPR) spectra were obtained at X-band $(9.5 \mathrm{GHz})$ fields using Bruker Elexsys E680 spectrometer equipped with a 4122SHQE resonator. Cyclic voltammetry (CV) measurements were carried out at room temperature with a Gamry Multipurpose instrument (Reference 600) interfaced to a PC. Cell viability assays were read on a Biotek Synergy Neo2 plate reader. Confocal images were obtained on a Leica SP5 laser scanning confocal microscope. Resin-embedded cells were microtomed using a Leica EM UC7/FC7 cryo-ultramicrotome and imaged on a Hitachi HD2300 cFEG STEM microscope with a high-angle annular dark field (HAADF) detector at an acceleration voltage of $80 \mathrm{kV}$. Cell irradiation was performed with a UVP $8 \mathrm{~W}, 365 \mathrm{~nm}$ UVLS-28 EL Series lamp.

\section{MALDI-TOF Sample Preparation}

MALDI-TOF measurements were performed on a Bruker AutoFlex-III time of flight instrument, operating in negative reflectron mode. AMNPs were suspended in ultrapure water to reach a final concentration of $0.01 \mathrm{mM}$. This solution was mixed with a saturated solution of the matrix (2,5-dihydroxybenzoinc acid, DHB) in water (50:50 volume ratio). This suspension was deposited on the stainless-steel sample holder and air-dried. Mass spectra were obtained by averaging the ions from 5,000 laser shots.

\section{Solid State NMR}

AMNPs were dried under vacuum. Approximate $80 \mathrm{mg}$ solid powder was loaded into a $4 \mathrm{~mm}$ rotor with special tools. The rotor was inserted into the probe from the top of the magnet, then a special cage was put immediately at the magnet top. The sample was spun to $15,000 \mathrm{~Hz}$. After tuning ${ }^{13} \mathrm{C}$ first, then ${ }^{1} \mathrm{H}$, the proton decoupled ${ }^{13} \mathrm{C}$ data were acquired. 


\section{Electron Paramagnetic Resonance Spectroscopy}

Continuous wave electron paramagnetic resonance (EPR) spectra were obtained at Xband $(9.5 \mathrm{GHz})$ fields using Bruker Elexsys E680 spectrometer equipped with a $4122 \mathrm{SHQE}$ resonator. Scans were performed with magnetic field modulation amplitude of $2 \mathrm{G}$ and non-saturating microwave power $1.544 \mathrm{~mW}, 32$ scans of average. Samples were contained in quartz tubes with I.D. $1.50 \mathrm{~mm}$ and O.D. $1.80 \mathrm{~mm}$.

\section{Preparation of AMNP-chitosan Film ${ }^{1}$}

To prepare the AMNP-chitosan film, AMNPs $(5 \mathrm{mg} / \mathrm{mL})$ were suspended in a chitosan solution $(0.5 \%, \mathrm{pH} 5.5)$, and $20 \mu \mathrm{L}$ of this suspension was spread onto a glassy carbon working electrode $\left(0.071 \mathrm{~cm}^{2}\right)$. The film was vacuum-dried at room temperature for 30 min and then immersed in phosphate buffer $(0.1 \mathrm{M}, \mathrm{pH} 7.0)$ for 10 min to neutralize the chitosan and form a hydrogel. In all studies, we used an AMNP-free chitosan film as a control. 

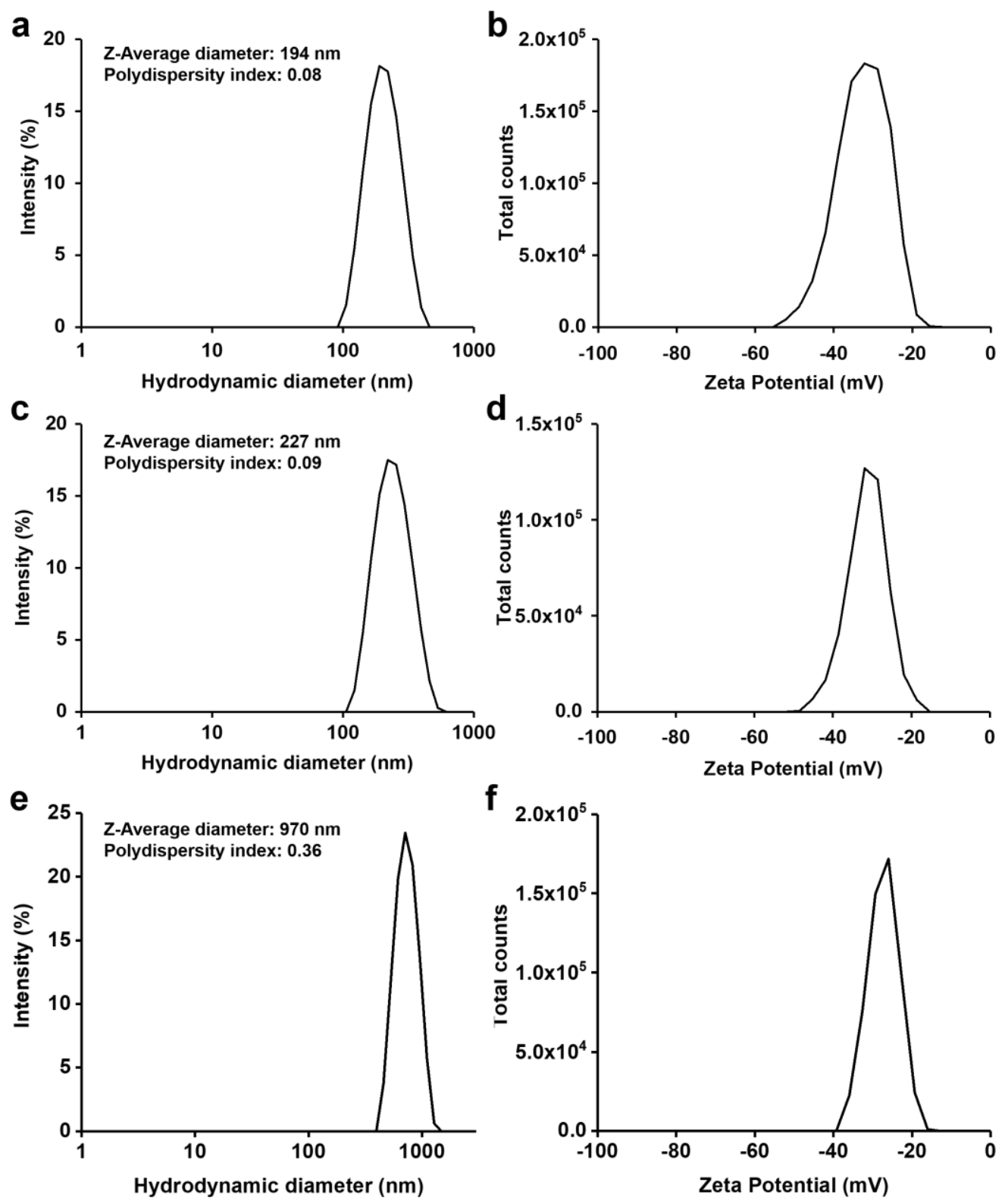

Figure S1. Average size of AMNPs was determined via dynamic light scattering in ultrapure water to be (a) $194 \mathrm{~nm}$ with a polydispersity index of 0.08 for AMNP-1; (c) $227 \mathrm{~nm}$ with a polydispersity index of 0.09 for AMNP-2; (e) $970 \mathrm{~nm}$ with a polydispersity index of 0.36 for AMNP-3. Zeta potential of (b) AMNP-1; (d) AMNP2; (f) AMNP-3. 


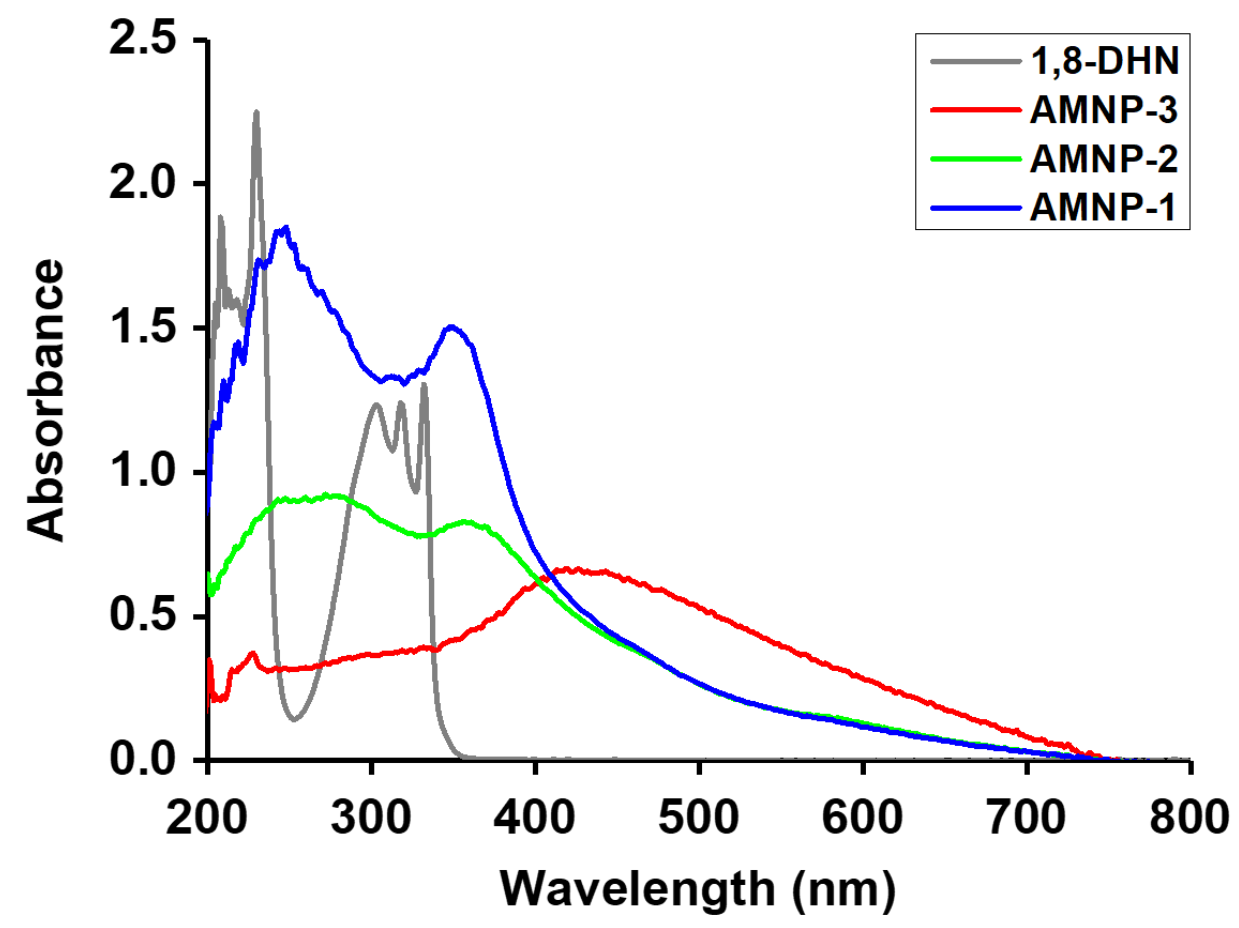

Figure S2. UV-Vis spectra of AMNPs and 1,8-DHN monomer. 

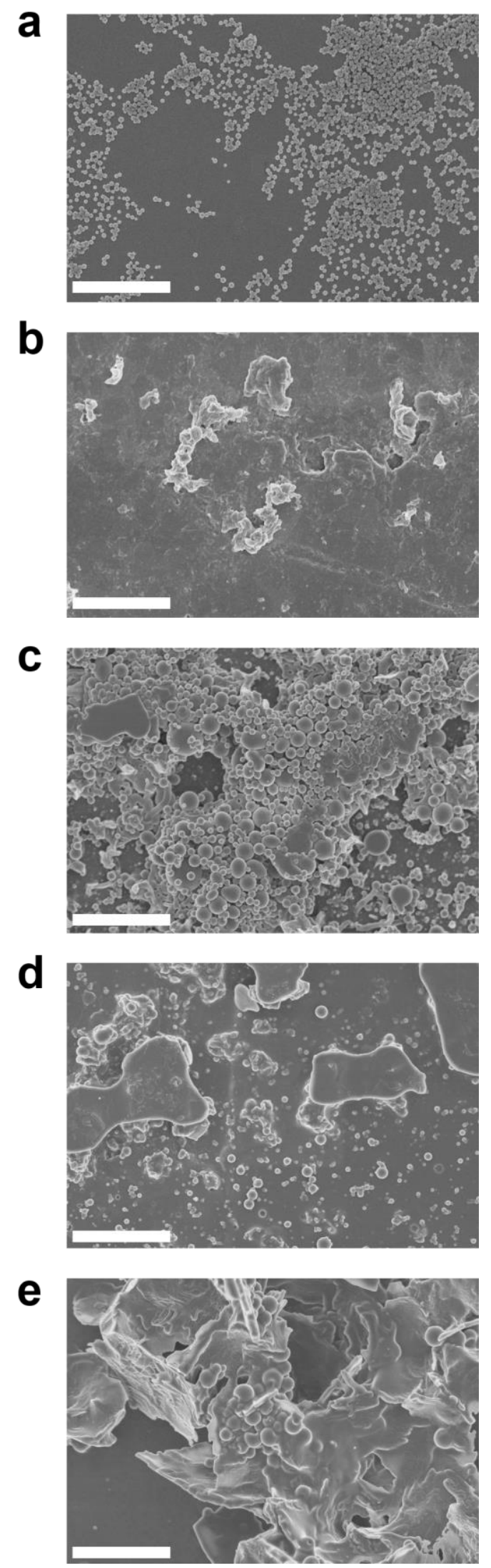

Figure S3. SEM micrographs of AMNP-1 with 0.5 molar ratio of $\mathrm{NaIO}_{4}$ to $1,8-\mathrm{DHN}$ in different solvents, (a) water; (b) acetonitrile; (c) methanol; (d) ethanol; and (e) dimethylformamide (DMF). Scale bars $3 \mu \mathrm{m}$. 

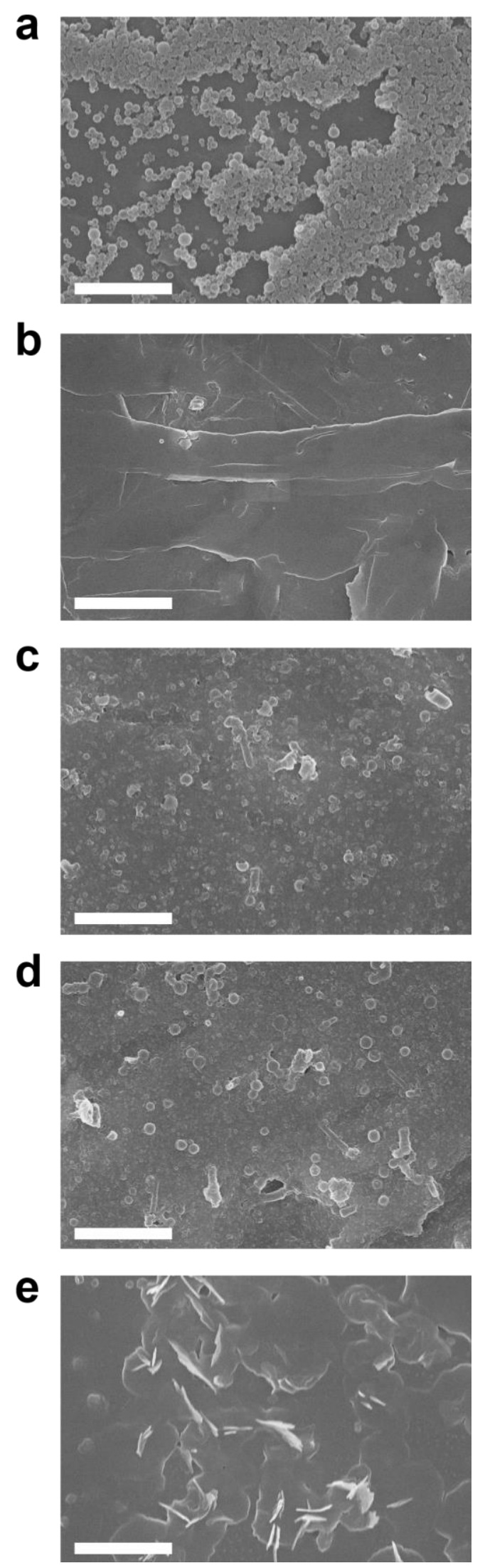

Figure S4. SEM micrographs of AMNP-2 with 0.2 molar ratio of $\mathrm{KMnO}_{4}$ to $1,8-\mathrm{DHN}$ in different solvents, (a) water; (b) acetonitrile; (c) methanol; (d) ethanol; and (e) DMF. Scale bars $3 \mu \mathrm{m}$. 

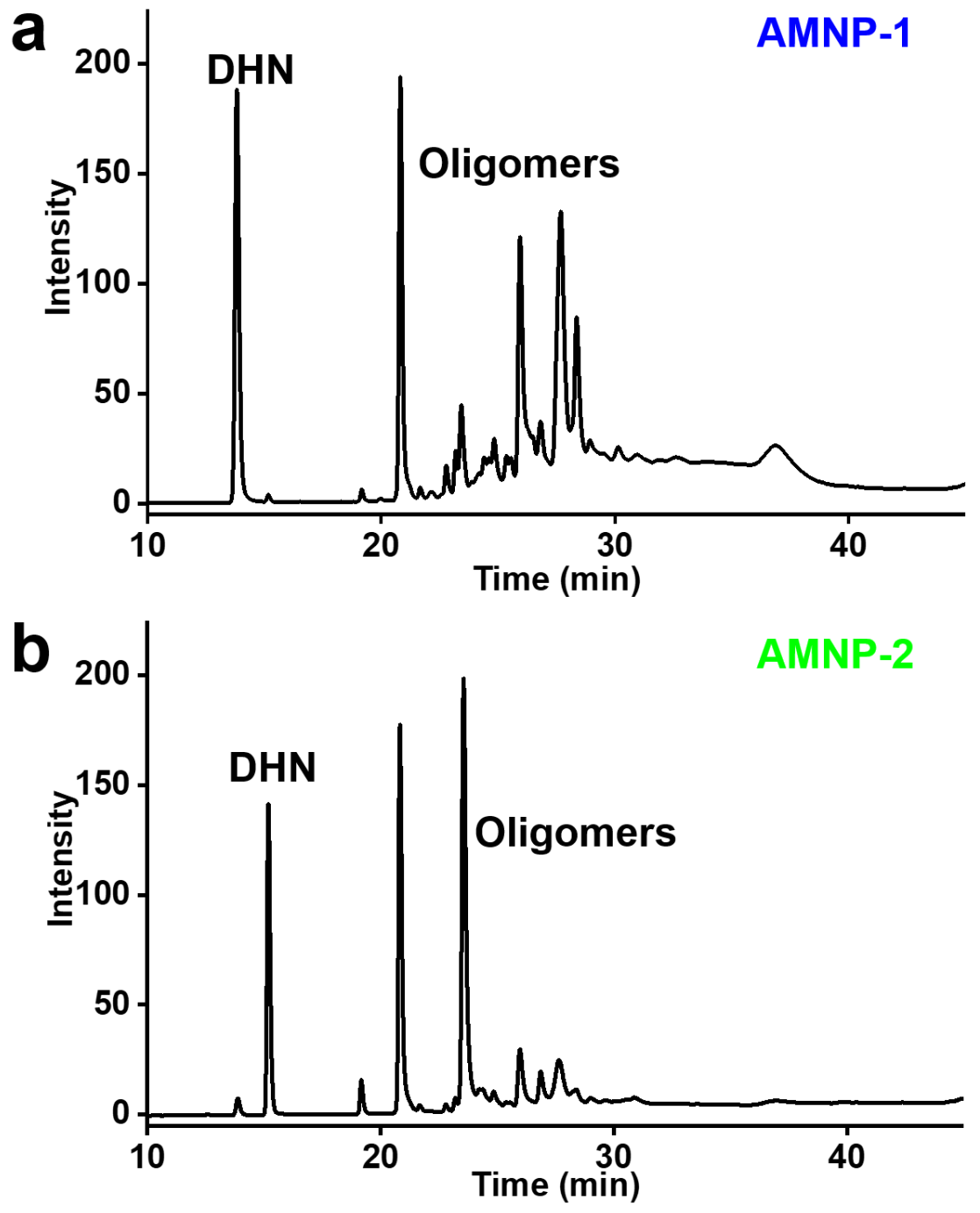

Figure S5. HPLC spectrum of (a) AMNP-1 with 0.5:1.0 molar ratio of $\mathrm{NaIO}_{4}$ to $\mathrm{DHN}$ (retention time at 14.0 min corresponds to DHN monomer); (b) AMNP-2 with 0.2:1.0 molar ratio of $\mathrm{KMnO}_{4}$ to $\mathrm{DHN}$ (retention time at 15.0 min corresponds to DHN monomer). AMNP-3 could not be dispersed in any of the organic solvents tested. 


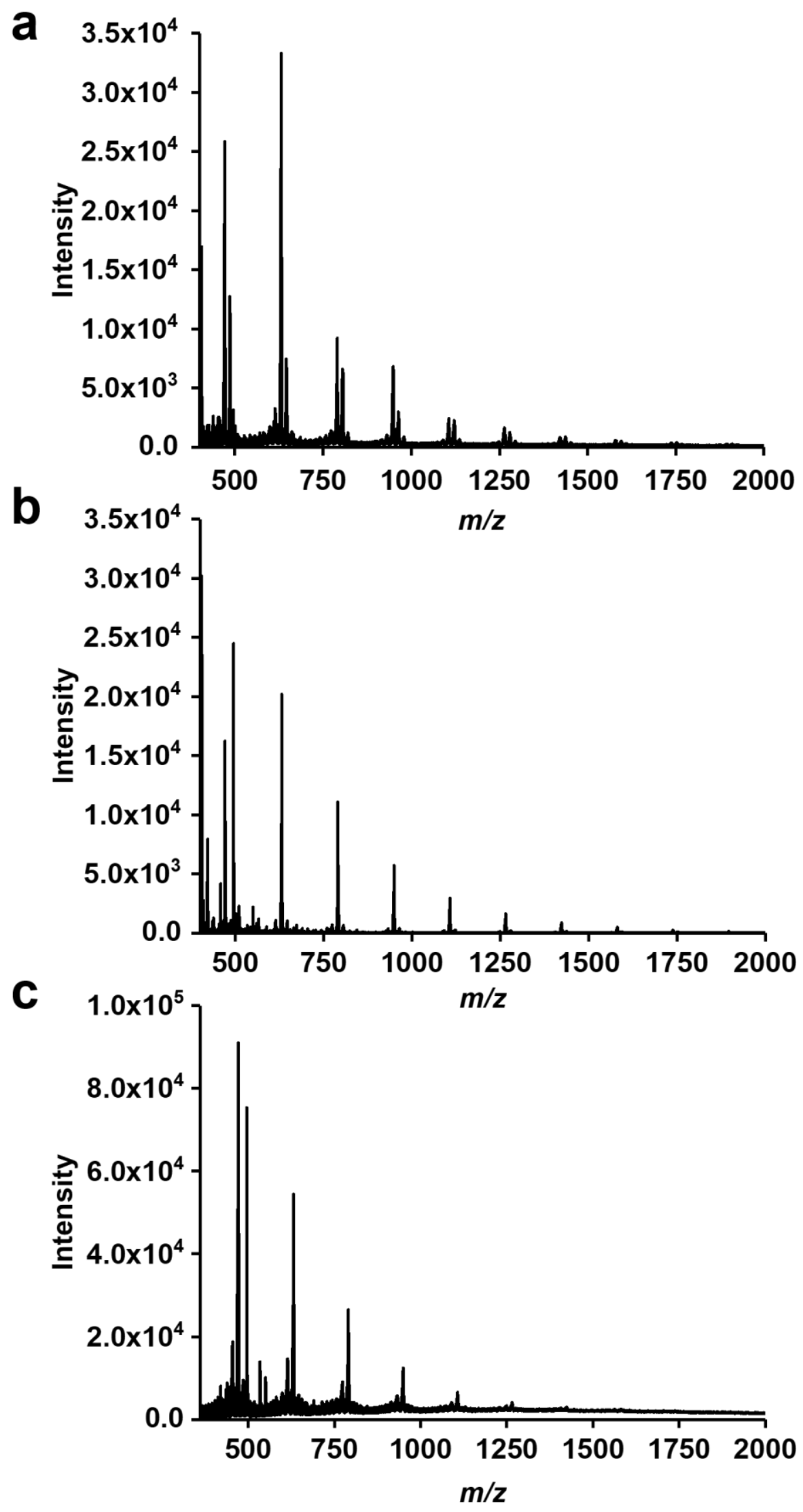

Figure S6. MALDI-TOF spectra of (a) AMNP-1; (b) AMNP-2; and (c) AMNP-3 in reflectron, negative mode. 


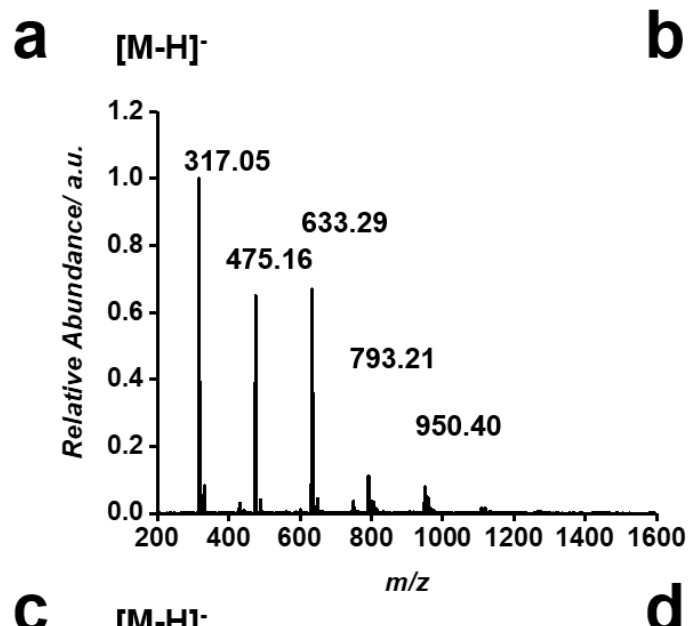

b $[\mathrm{M}-\mathrm{H}]^{-}$

C $[\mathrm{M}-\mathrm{H}]$
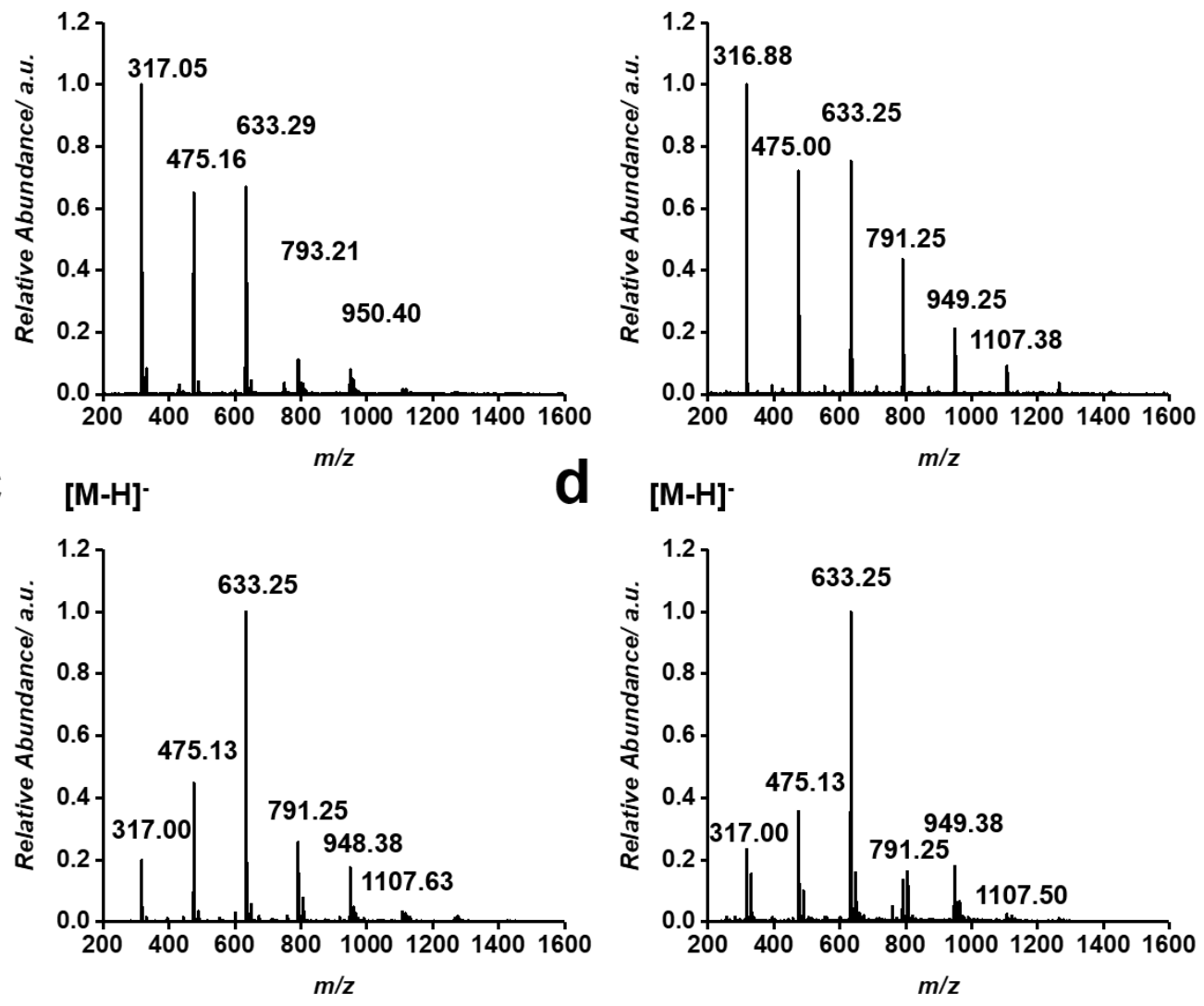

Figure S7. ESI-MS spectra of AMNP-1 with different molar ratios of $\mathrm{NaIO}_{4}$ to 1,8DHN monomer at (a) 0.2:1.0; (b) 0.5:1.0; (c) 1.0:1.0; and (d) 1.5:1.0. 


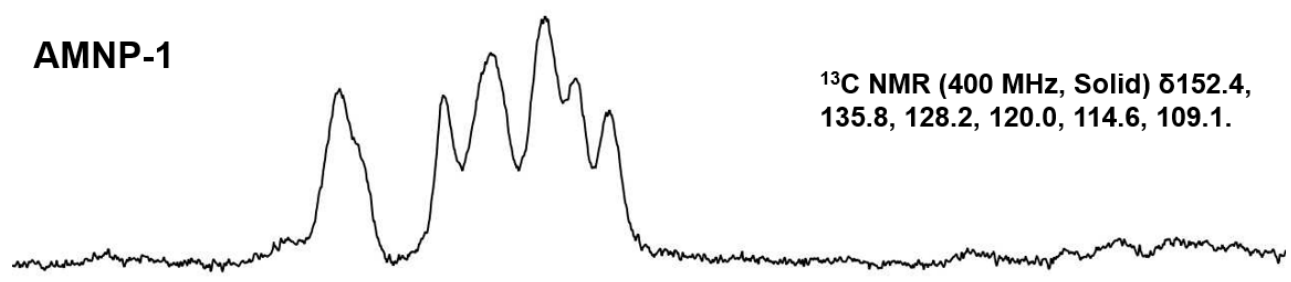

AMNP-2

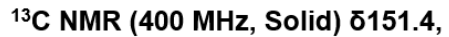

135.9, 128.6, 118.9, 114.7, 109.4 .

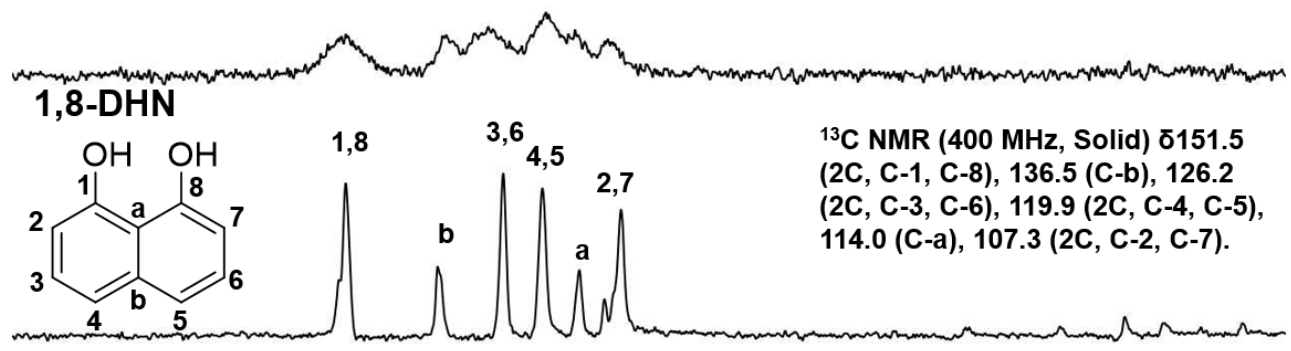

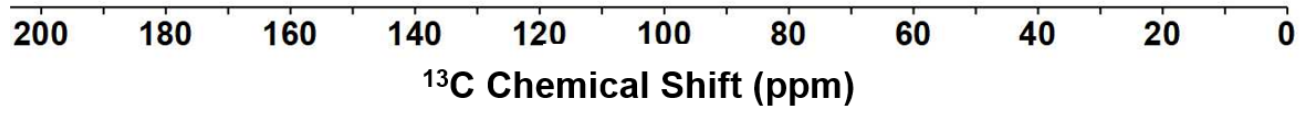

Figure S8. ${ }^{13} \mathrm{C}$ solid-state NMR spectra of AMNP-1, AMNP-2, and 1,8-DHN monomer.
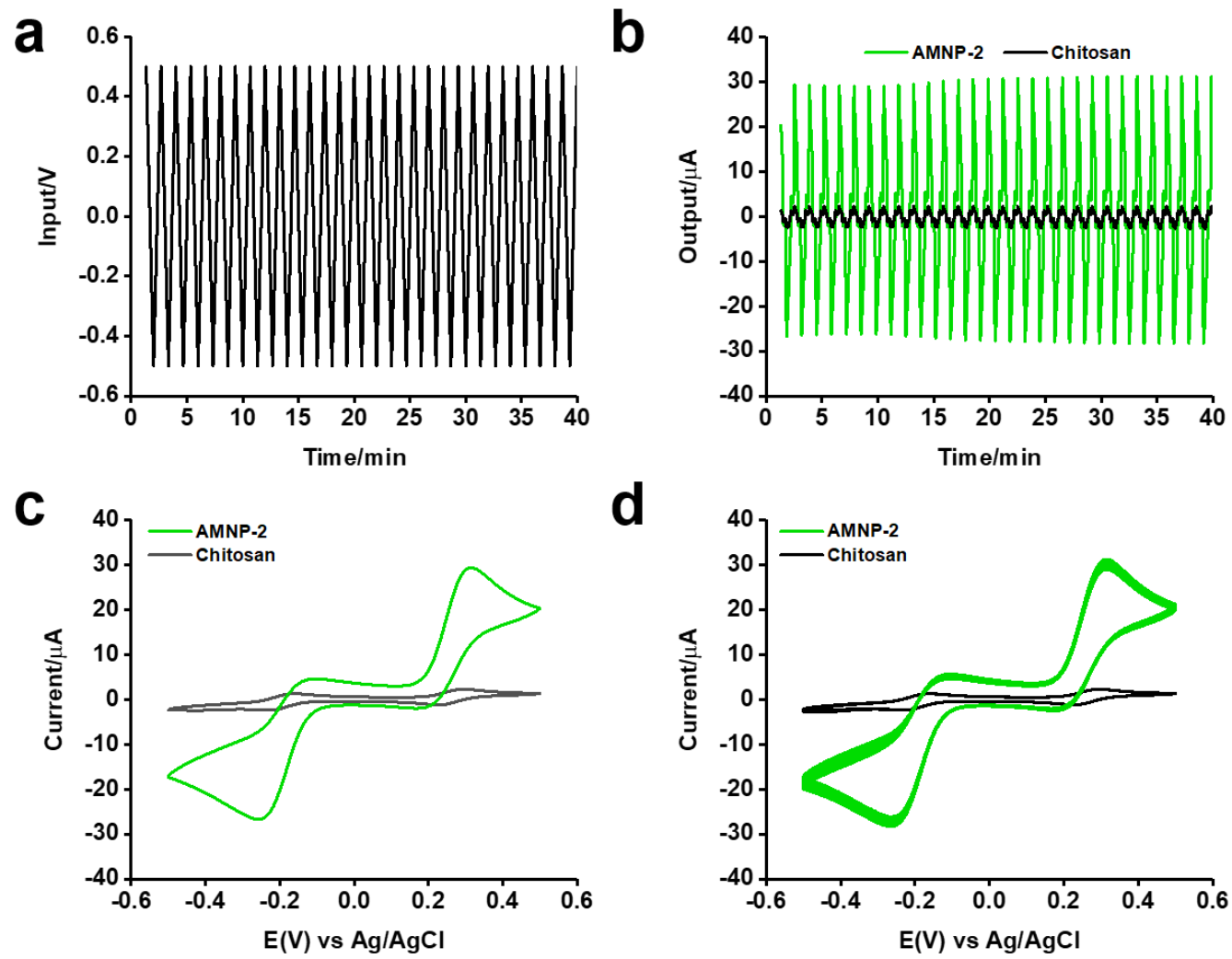

Figure S9. Mediated electrochemical probing (MEP) to characterize redox properties of AMNP-2. Chitosan was applied as a control. (a) electrical input (voltage) and electrical output (current); (b) time domain; (c) potential domain (single cycle); and (d) potential domain (30 cycles). 

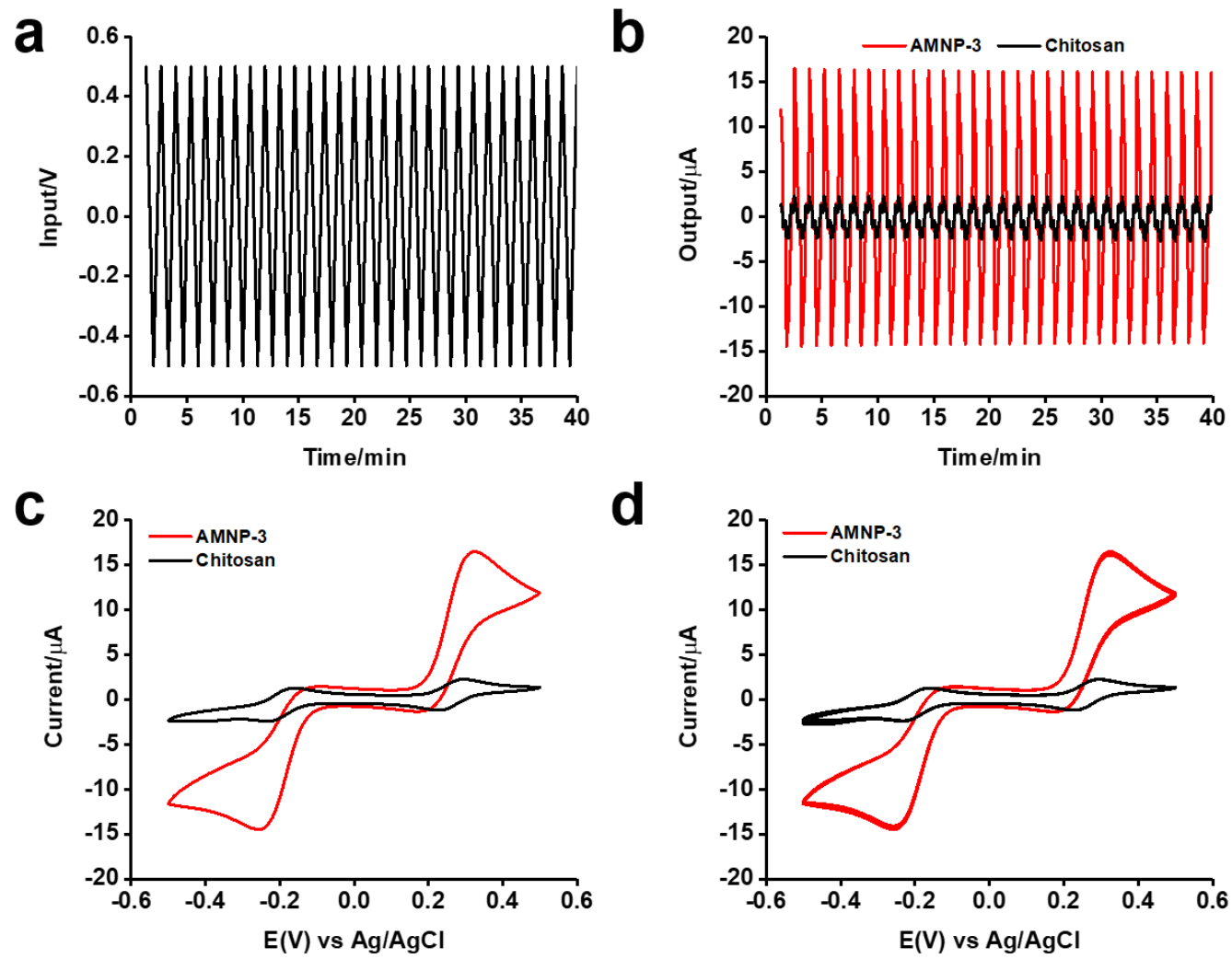

Figure S10. Mediated electrochemical probing (MEP) to characterize redox properties of AMNP-3. Chitosan was applied as a control. (a) electrical input (voltage) and electrical output (current); (b) time domain; (c) potential domain (single cycle); and (d) potential domain (30 cycles).

Phenol<smiles>COc1c(C(C)(C)C)ccc2ccc(-c3ccc4ccc(C(C)(C)C)c(O)c4c3O)c(O)c12</smiles><smiles>CC(C)(C)c1ccc2ccc(-c3ccc(O)c4c(O)c(C(C)(C)C)ccc34)c(O)c2c1O</smiles>

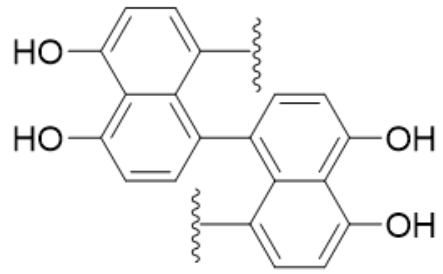

Quinone<smiles>Cc1ccc2c(c1O)C(=O)C(=C1C=Cc3ccc(C(C)(C)C)c(O)c3C1=O)C=C2</smiles><smiles>CC(C)c1ccc2c(c1O)C(=O)C(=C1C=CC(=O)c3c1ccc(C(C)(C)C)c3O)C=C2</smiles>

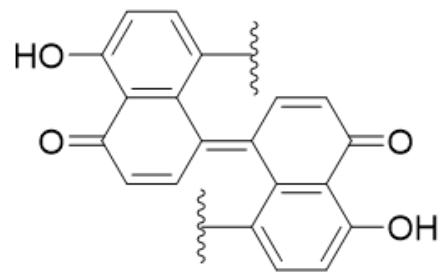

Figure S11. Phenol/quinone structures in AMNPs. 

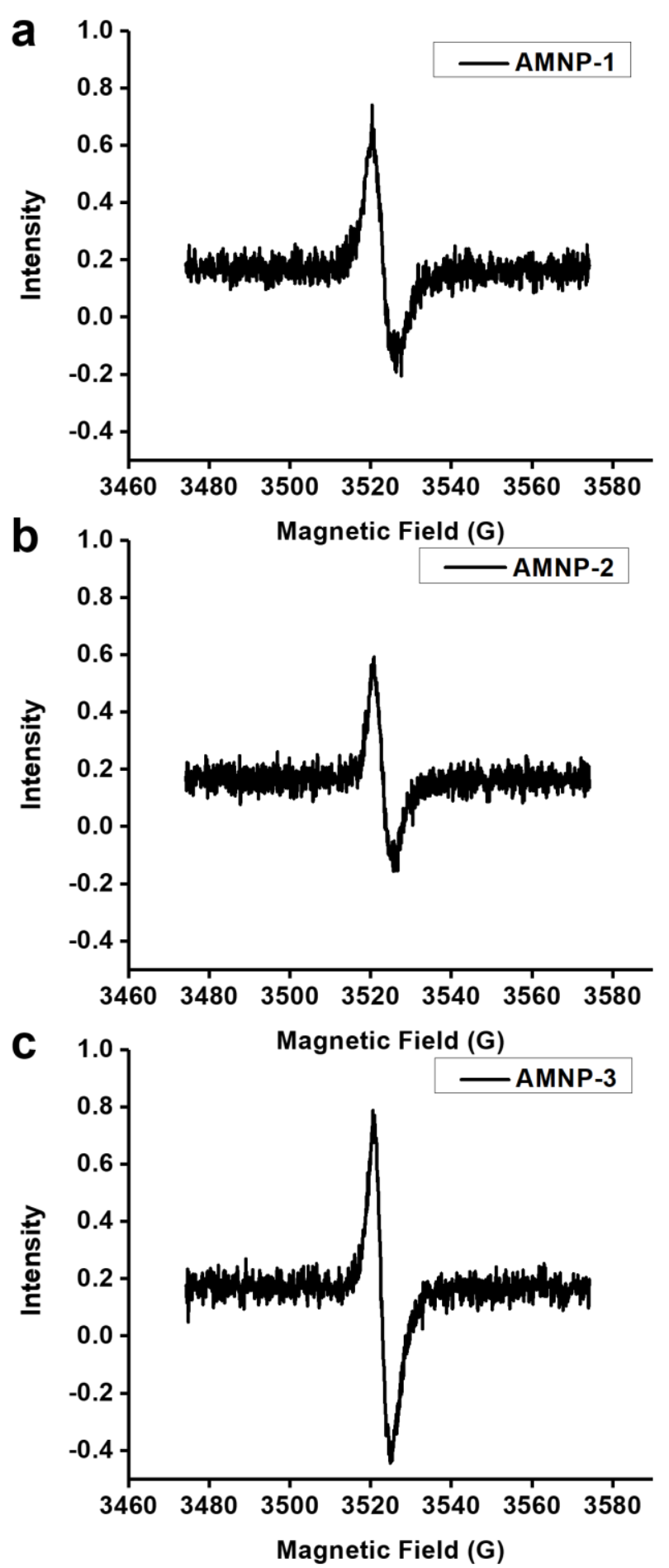

Figure S12. Electron paramagnetic resonance (EPR) spectra of AMNPs. 

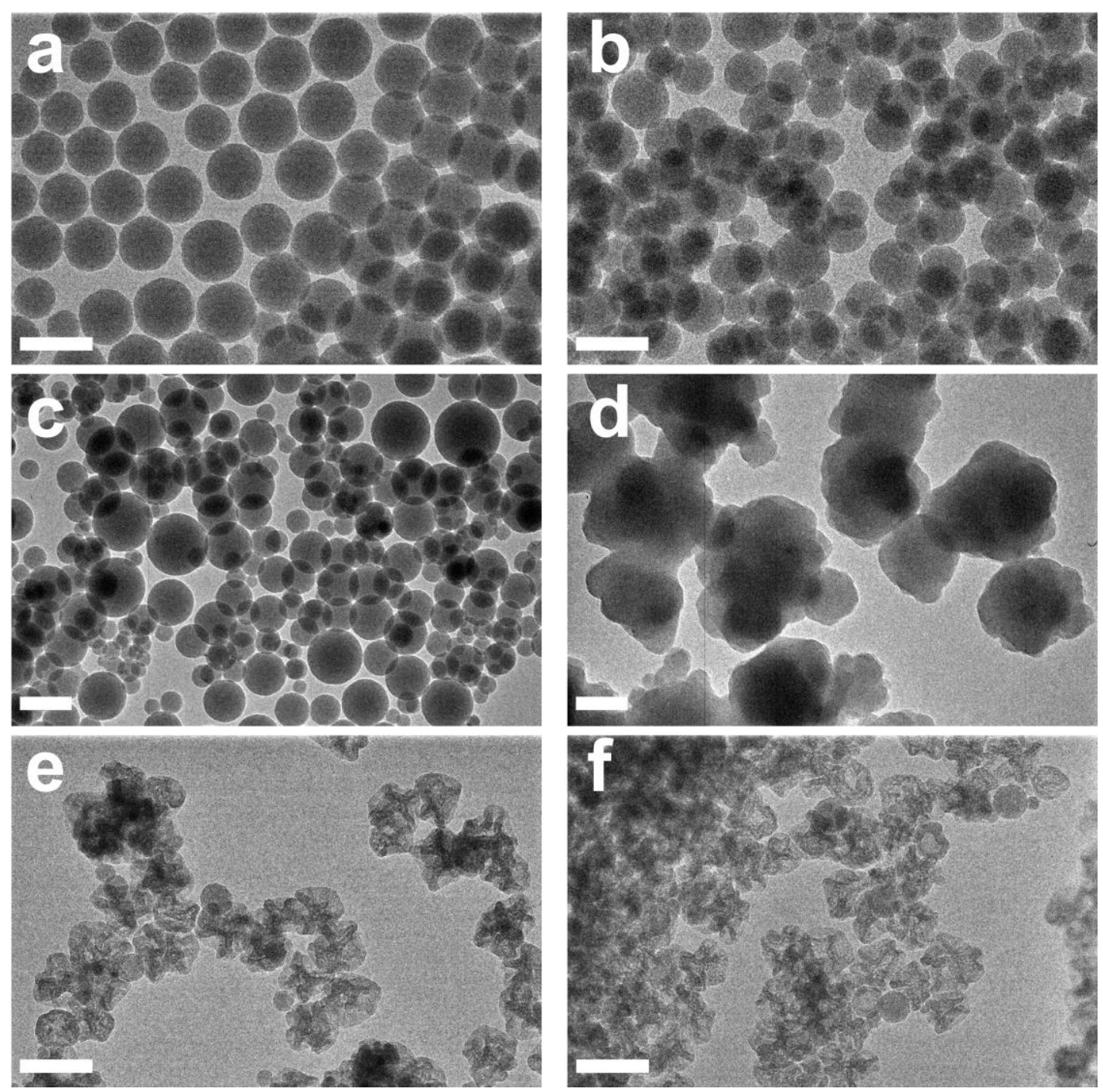

Figure S13. TEM micrographs of antioxidants used in DPPH assay. (a) spherical AMNP-1 synthesized using molar ratio of $\mathrm{NaIO}_{4}$ to 1,8-DHN at 0.5:1.0; (b) PDA-NPs; (c) AMNP-2; (d) AMNP-3; (e) walnut-like AMNP-1 synthesized using molar ratio of $\mathrm{NaIO}_{4}$ to 1,8-DHN at 1.0:1.0; and (f) walnut-like AMNP-1 synthesized using molar ratio of $\mathrm{NaIO}_{4}$ to $1,8-\mathrm{DHN}$ at 1.5:1.0. Scale bars $200 \mathrm{~nm}$. 

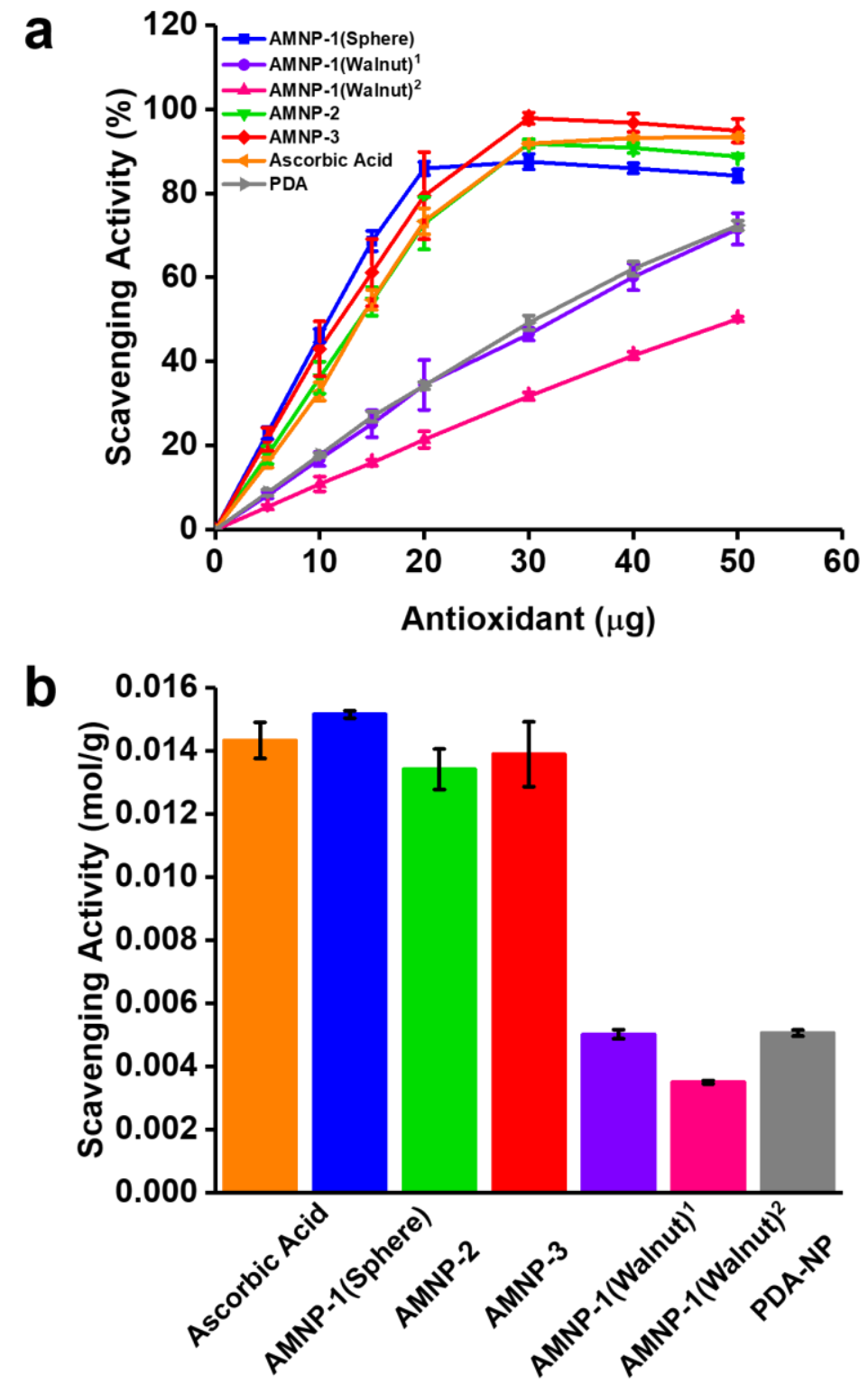

Figure S14. Radical scavenging by AMNPs compared to PDA-NPs and ascorbic acid. (a) DPPH radical scavenging activity of antioxidants; (b) calculated amount of quenched DPPH per gram of antioxidant (walnut ${ }^{1}$ AMNP-1 in Figure S13e and walnut ${ }^{2}$ AMNP-1 in Figure S13f). 

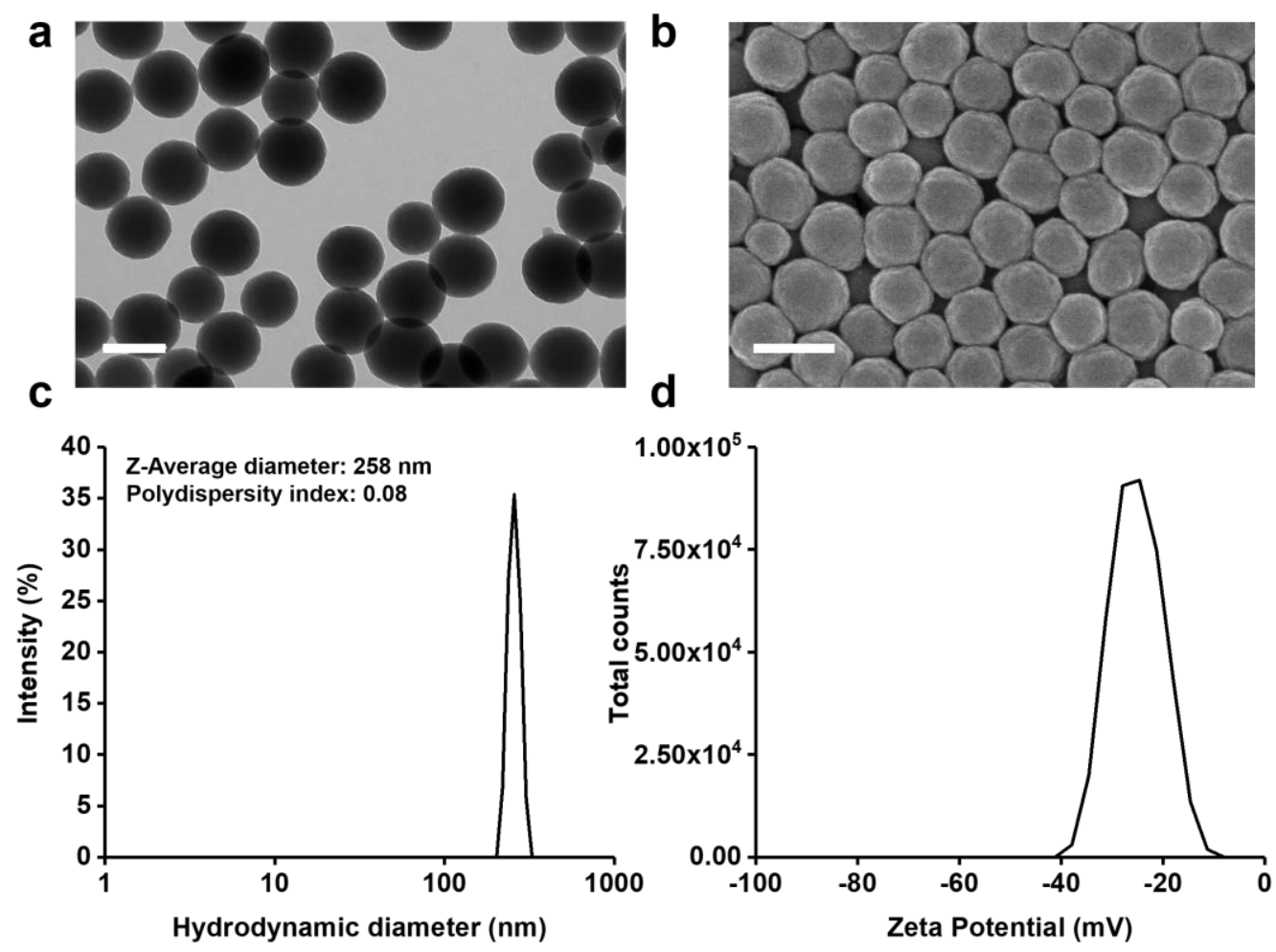

Figure S15. (a) TEM and (b) SEM micrographs of PDA-NPs, scale bars $200 \mathrm{~nm}$. Average size of PDA-NPs was determined via dynamic light scattering in ultrapure water to be (c) $258 \mathrm{~nm}$ with polydispersity index of 0.08 . (d) Zeta potential.
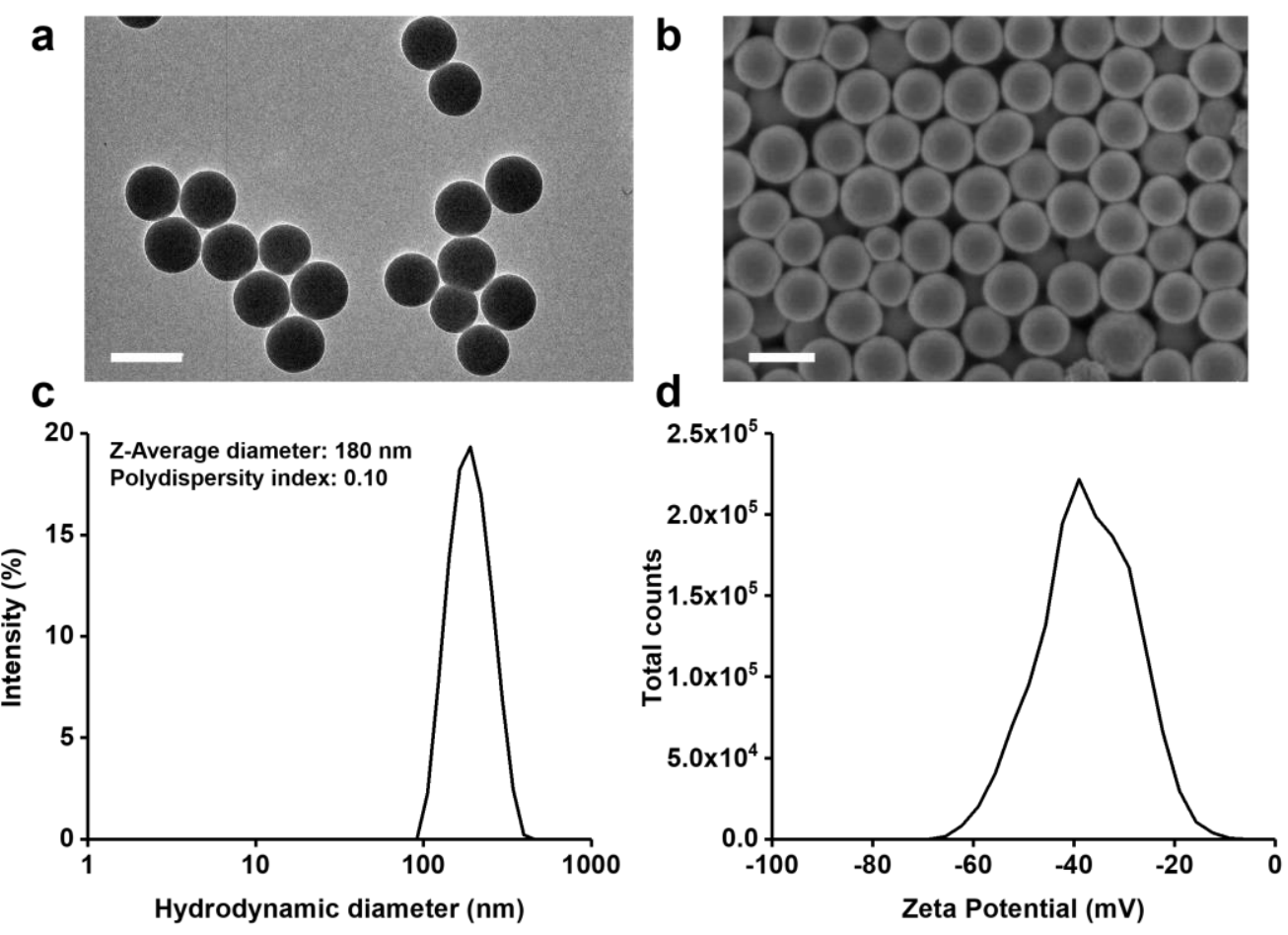

Figure S16. (a) TEM and (b) SEM micrographs of silica nanoparticles, scale bars 200 $\mathrm{nm}$. Average size of silica nanoparticles was determined via dynamic light scattering in ultrapure water to be (c) $180 \mathrm{~nm}$ with polydispersity index of 0.10 . (d) Zeta potential. 

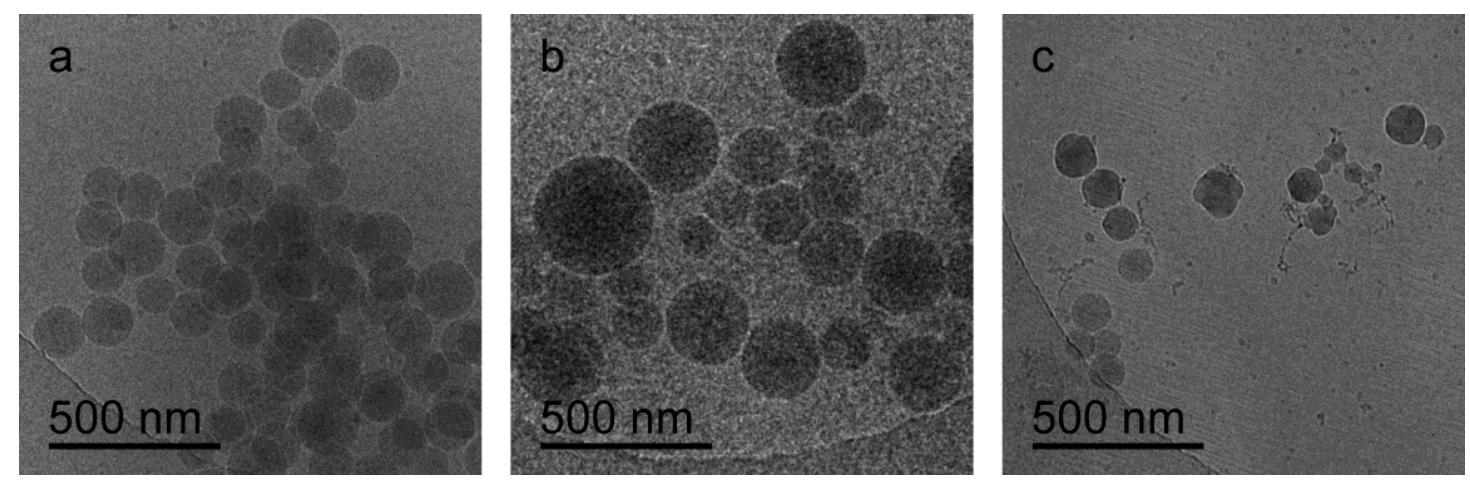

Figure S17. CryoTEM of AMNPs in cell media, (a) AMNP-1; (b) AMNP-2; and (c) AMNP-3. Particles were incubated in cell culture media at $0.04 \mathrm{mg} / \mathrm{mL}$ for 48 hours, then $4 \mu \mathrm{L}$ of suspended AMNP particles was vitrified using a Vitrobot Mark III (ThermoFisher Scientific) operating at $8{ }^{\circ} \mathrm{C}$ with $>95 \%$ relative humidity. TEM grids were surface plasma treated before the vitrification procedure. 


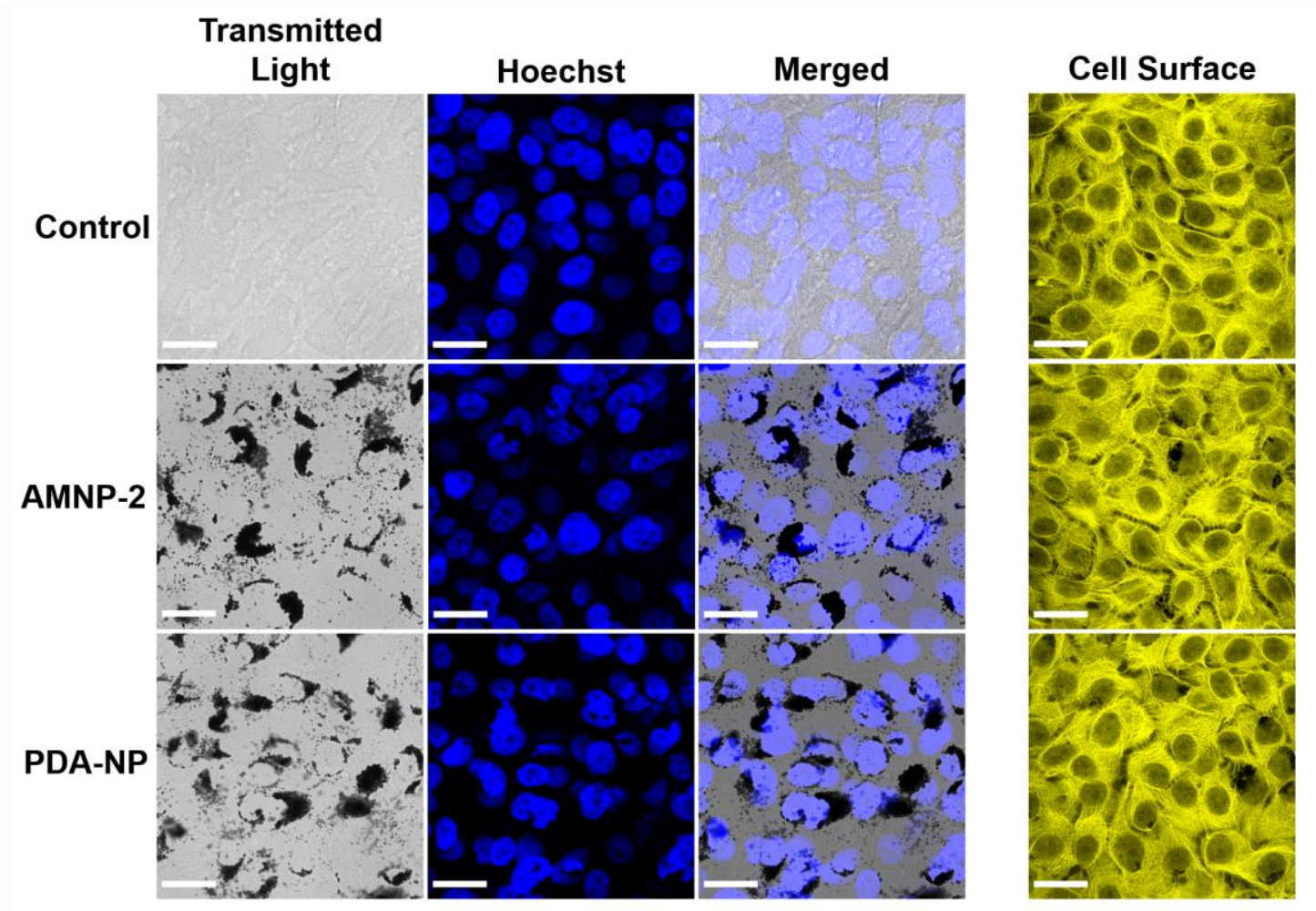

Figure S18. NHEK cells were differentiated in $1.2 \mathrm{mM} \mathrm{CaCl}_{2}$ for 24 hours and then incubated with the vehicle, or $0.04 \mathrm{mg} / \mathrm{mL}$ AMNP-2 or PDA-NP. Perinuclear caps are apparent as black crescents in the transmitted light images. Nuclei are stained with Hoechst (blue). Images show a single section through the center of the cell layer (left three columns). To better view the morphological changes at the surface of the differentiating cells, they were stained with CellTracker ${ }^{\mathrm{TM}}$ Orange CMRA dye (ThermoFisher), shown in yellow (rightmost column). Scale bars $25 \mu \mathrm{m}$. 

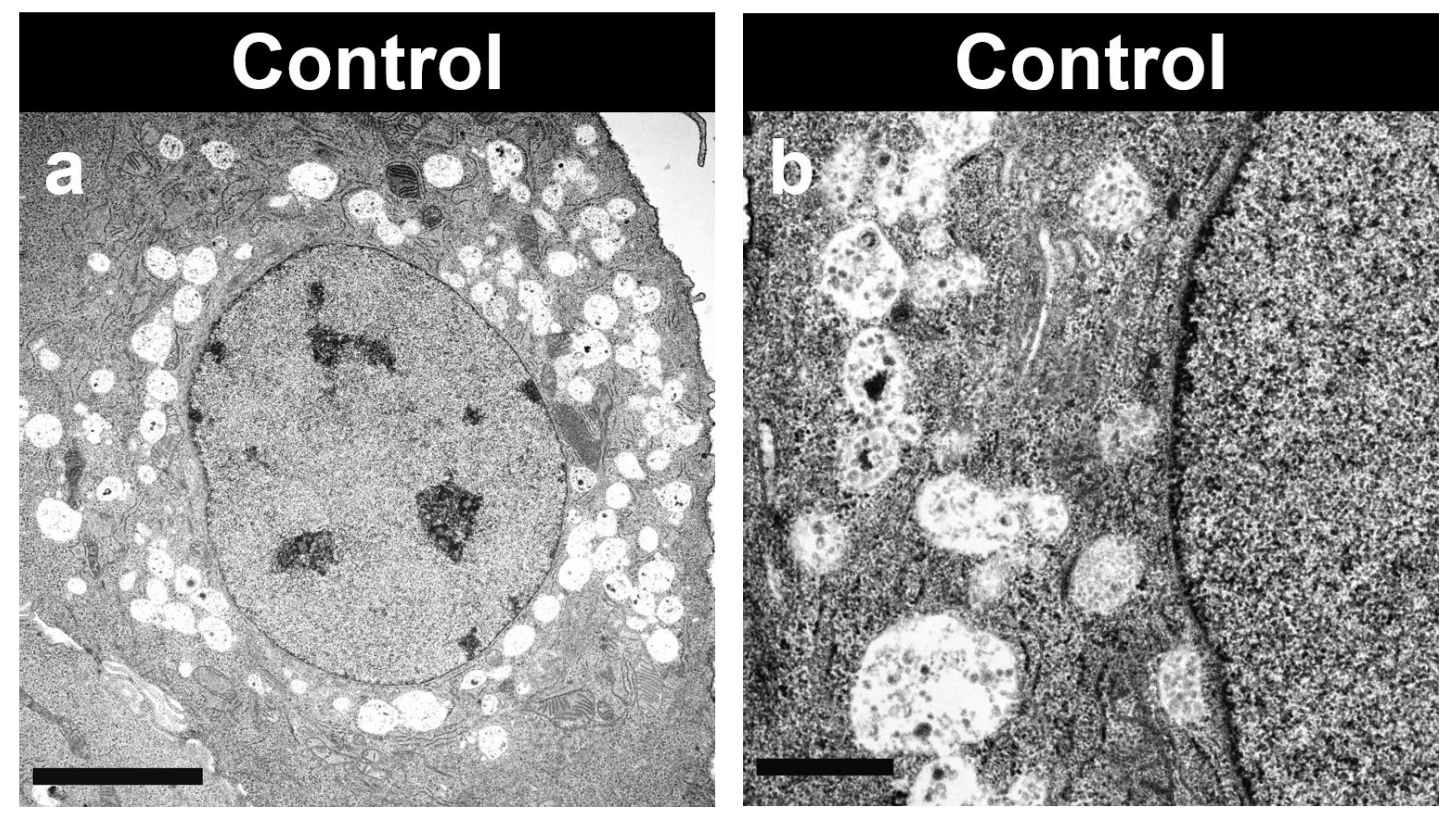

Figure S19. STEM micrographs of monolayer NHEK cells treated with the vehicle (water) for 48 hours, resin-embedded, and sectioned to $60 \mathrm{~nm}$ thick. Images were acquired using a high-angle annular dark field (HAADF) detector and the contrast inverted to simulate traditional bright-field TEM images. (a) scale bar $5 \mu \mathrm{m}$, (b) scale bar $1 \mu \mathrm{m}$.
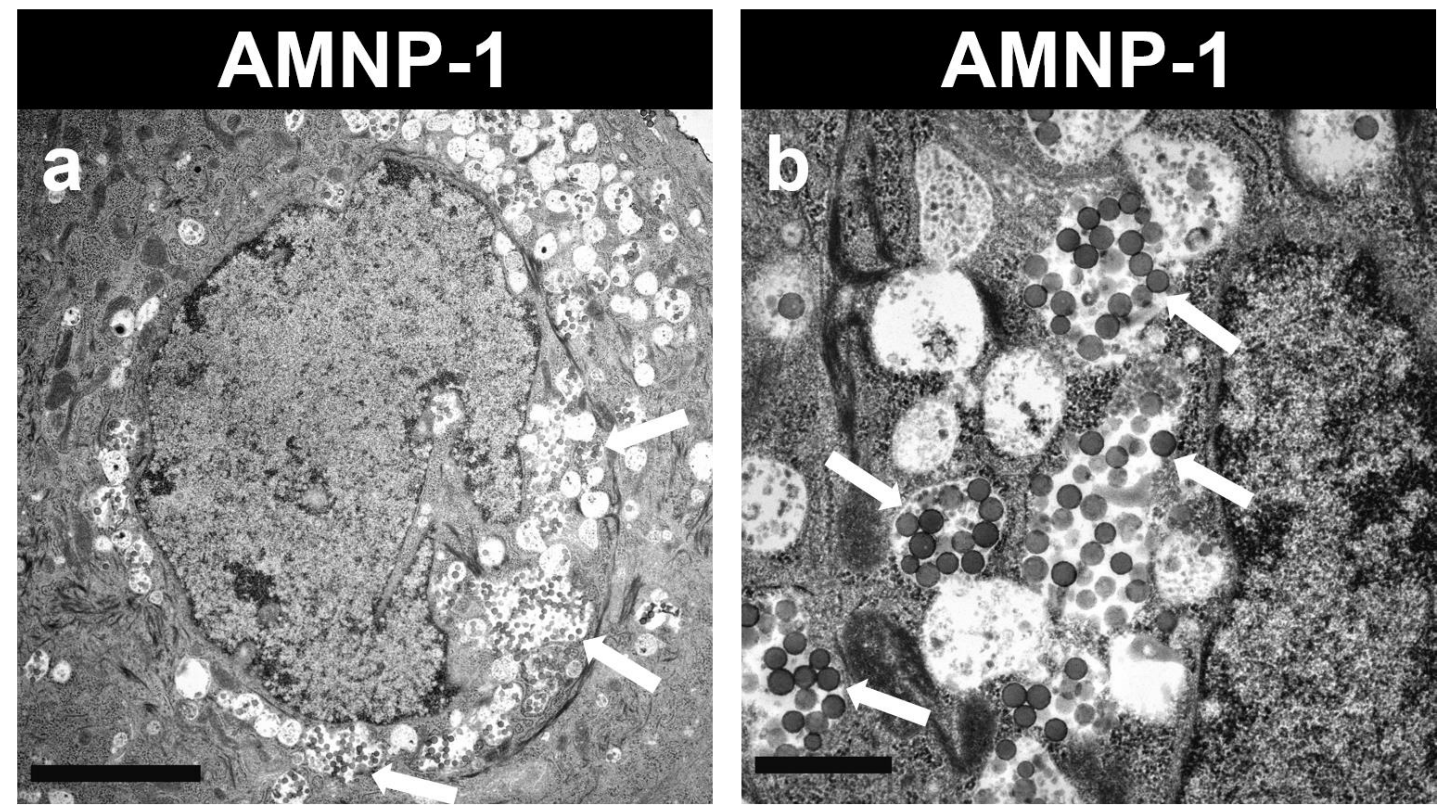

Figure S20. STEM micrographs of monolayer NHEK cells treated with $0.04 \mathrm{mg} / \mathrm{mL}$ AMNP-1 for 48 hours, resin-embedded, and sectioned to $60 \mathrm{~nm}$ thick. Images were acquired using an HAADF detector and the contrast inverted to simulate traditional bright-field TEM images. (a) scale bar $5 \mu \mathrm{m}$, (b) scale bar $1 \mu \mathrm{m}$. Arrows point to nanoparticles inside the cell. 

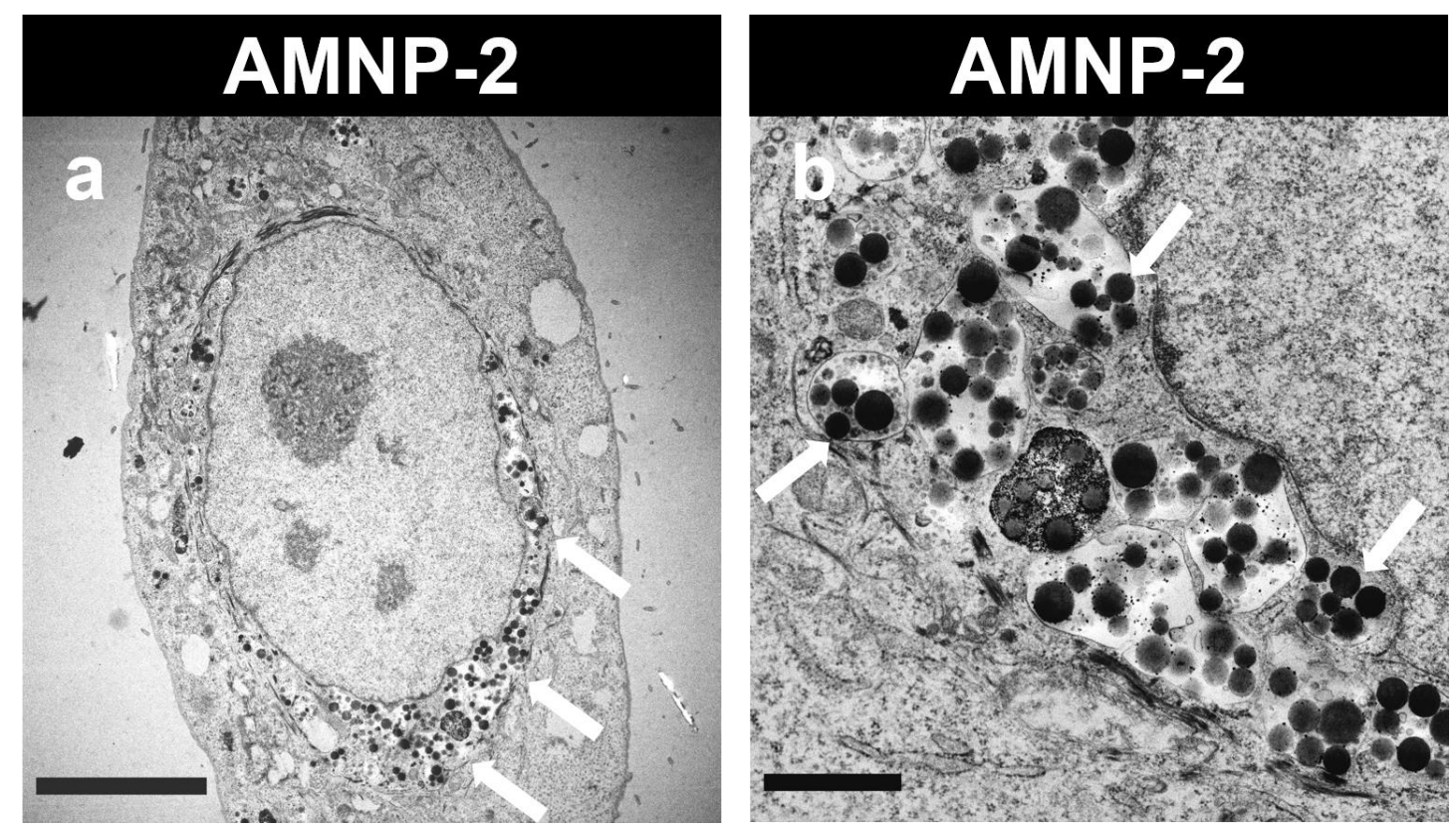

Figure S21. STEM micrographs of monolayer NHEK cells treated with $0.04 \mathrm{mg} / \mathrm{mL}$ AMNP-2 for 48 hours, resin-embedded, and sectioned to $60 \mathrm{~nm}$ thick. Images were acquired using an HAADF detector and the contrast inverted to simulate traditional bright-field TEM images. (a) scale bar $5 \mu \mathrm{m}$, (b) scale bar $1 \mu \mathrm{m}$. Arrows point to nanoparticles inside the cell.
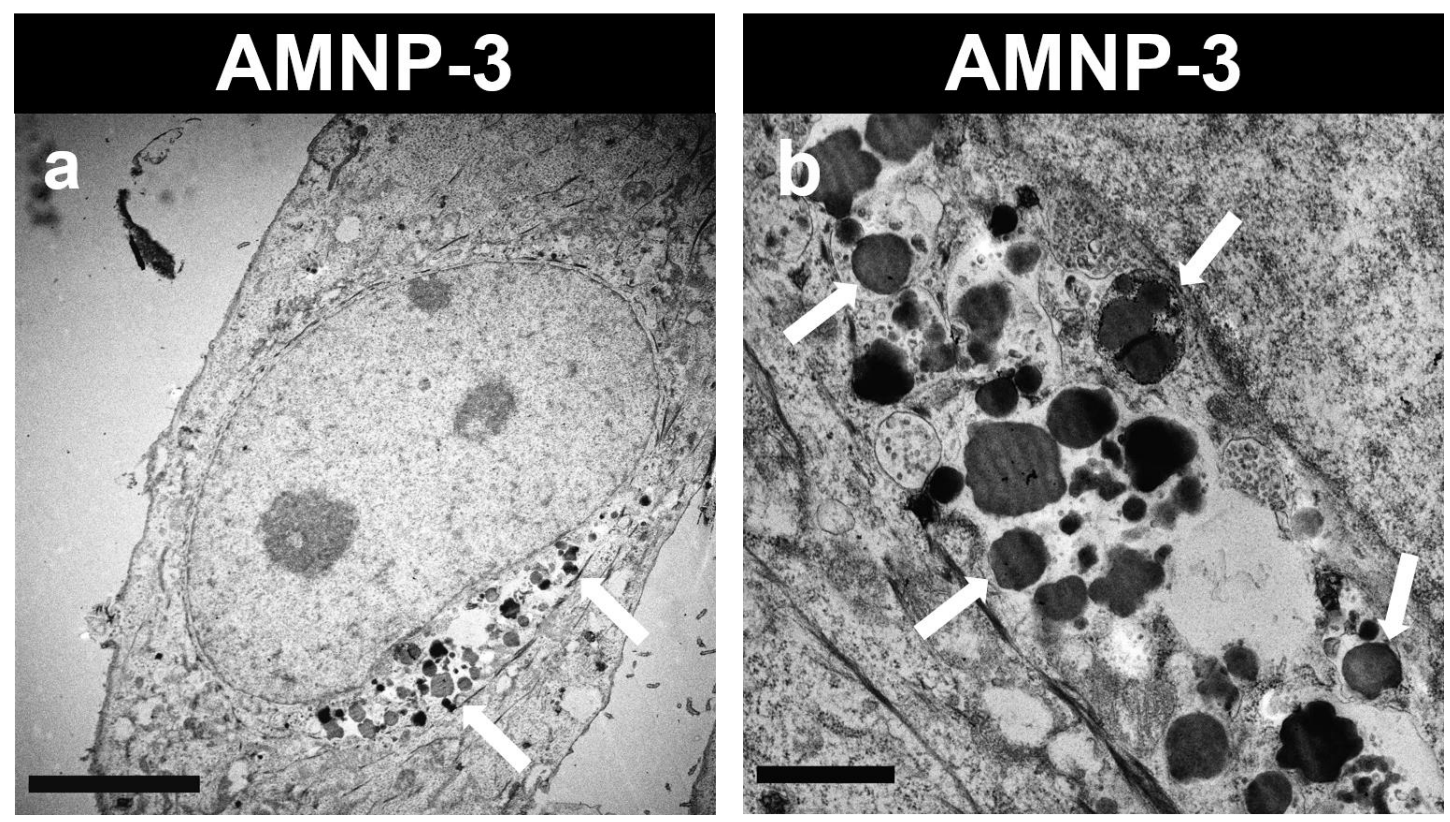

Figure S22. STEM micrographs of monolayer NHEK cells treated with $0.04 \mathrm{mg} / \mathrm{mL}$ AMNP-3 for 48 hours, resin-embedded, and sectioned to $60 \mathrm{~nm}$ thick. Images were acquired using an HAADF detector and the contrast inverted to simulate traditional bright-field TEM images. (a) scale bar $5 \mu \mathrm{m}$, (b) scale bar $1 \mu \mathrm{m}$. Arrows point to nanoparticles inside the cell. 

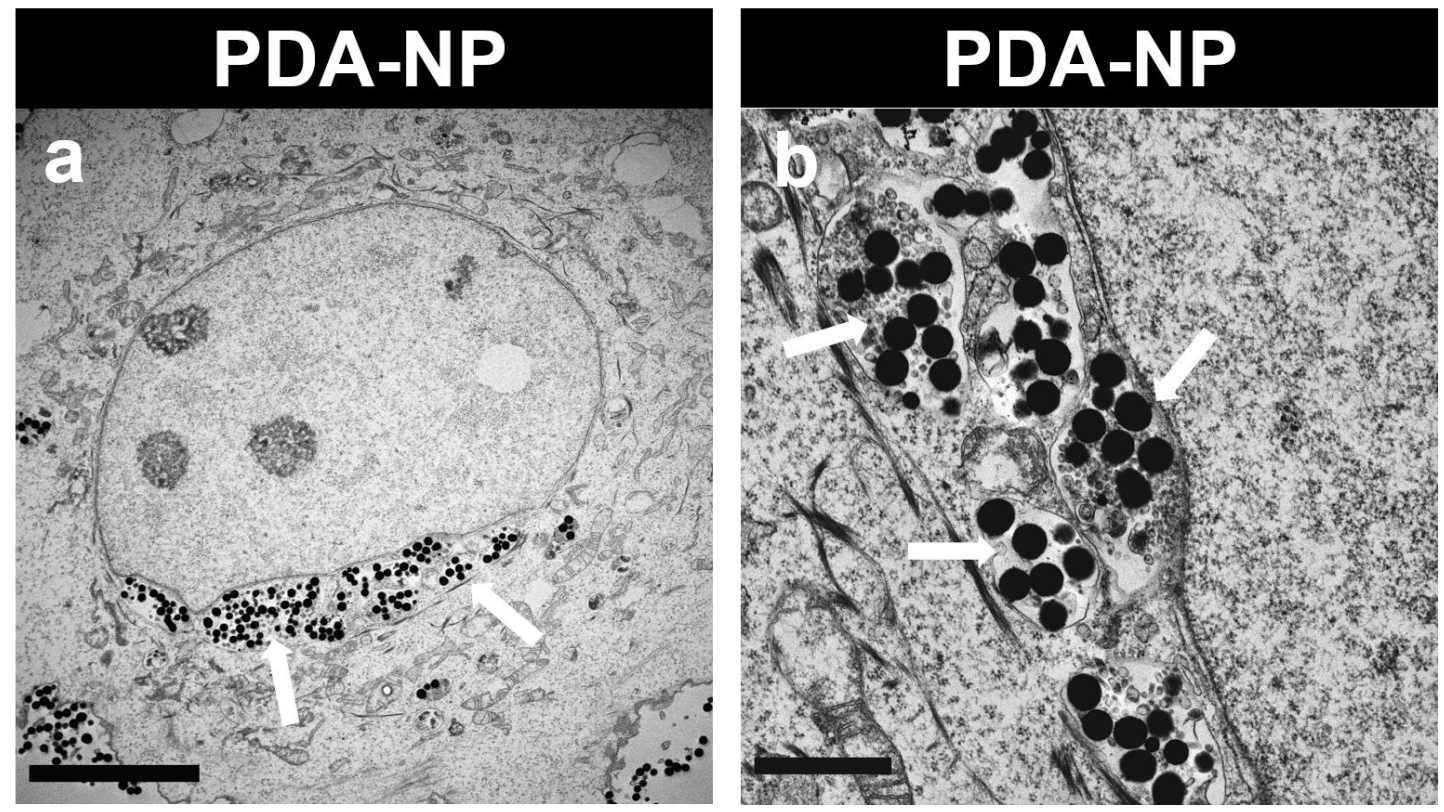

Figure S23. STEM micrographs of monolayer NHEK cells treated with $0.04 \mathrm{mg} / \mathrm{mL}$ PDA-NP for 48 hours, resin-embedded, and sectioned to $60 \mathrm{~nm}$ thick. Images were acquired using an HAADF detector and the contrast inverted to simulate traditional bright-field TEM images. (a) scale bar $5 \mu \mathrm{m}$, (b) scale bar $1 \mu \mathrm{m}$. Arrows point to nanoparticles inside the cell.
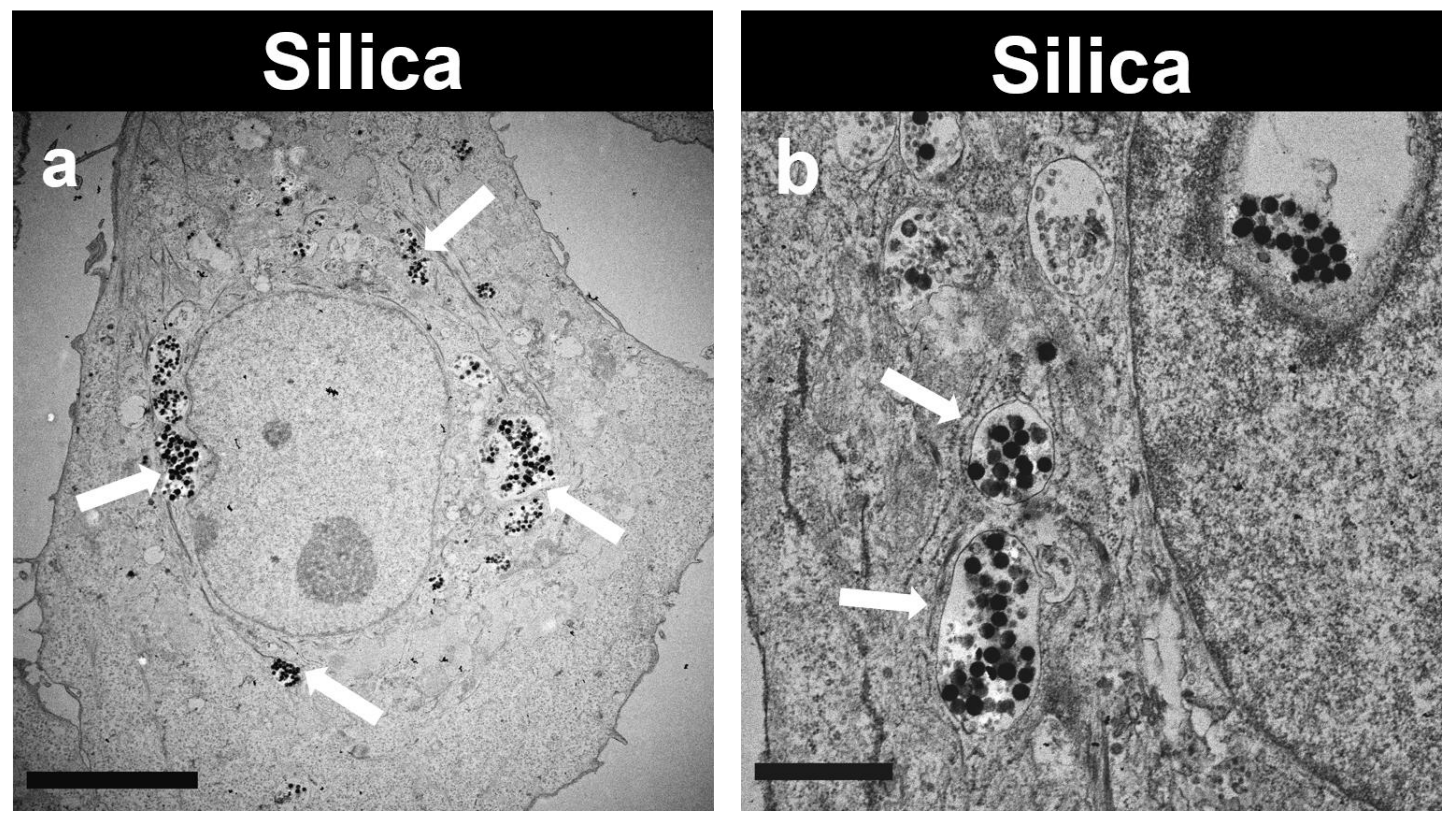

Figure S24. STEM micrographs of monolayer NHEK cells treated with $0.04 \mathrm{mg} / \mathrm{mL}$ silica nanoparticles for 48 hours, resin-embedded, and sectioned to $60 \mathrm{~nm}$ thick. Images were acquired using an HAADF detector and the contrast inverted to simulate traditional bright-field TEM images. (a) scale bar $5 \mu \mathrm{m}$, (b) scale bar $1 \mu \mathrm{m}$. Arrows point to nanoparticles inside the cell. 


\section{REFERENCES}

(1) Kang, M.; Kim, E.; Temocin, Z.; Li, J. Y.; Dadachova, E.; Wang, Z.; Panzella, L.; Napolitano, A.; Bentley, W. E.; Payne, G. F. Reverse Engineering To Characterize Redox Properties: Revealing Melanin's Redox Activity through Mediated Electrochemical Probing. Chem. Mater. 2018, 30, 5814-5826. 